\title{
Survival Analysis of Drug Abuse Relapse in Addiction Treatment Centers
}

\author{
Aziz Kassani ${ }^{1}$; Mohsen Niazi ${ }^{2,3}$; Jafar Hassanzadeh ${ }^{1, *} ;$ Rostam Menati ${ }^{2,3}$ \\ ${ }_{1}^{1}$ Research Center for Health Sciences, Department of Epidemiology, School of Health, Shiraz University of Medical Sciences, Shiraz, IR Iran \\ ${ }^{2}$ Faculty of Humanities, University of Kashan, Kashan, IR Iran \\ ${ }^{3}$ Research Center for Prevention of Socio-Psychological Injuries, Ilam University of Medical Sciences, Ilam, IR Iran \\ ${ }^{*}$ Corresponding author: Jafar Hassanzadeh, Research Center for Health Sciences, Department of Epidemiology, School of Health, Shiraz University of Medical Sciences, Shiraz, IR Iran. \\ Tel:+98-9301523081, E-mail: jhasanzad@sums.ac.ir \\ Received: September 7, 2014; Revised: December 15, 2014; Accepted: January 3, 2015
}

\begin{abstract}
Background: Drug abuse is a chronic and enduring phenomenon, which is among the important challenging public health problems. One of the main aspects in drug abuse is the relapse.

Objectives: The aims of this study were to estimate the time to relapse (survival rate) and to evaluate some of its associated variables by survival analysis.

Patients and Methods: This research was conducted in four addiction treatment centers on 140 self-referred addicts in Ilam city, Iran, in 2012. Cluster sampling method was used for selecting the samples and data were collected by interview and referring to the subjects' records. The gathered data were analyzed through the life table, Kaplan-Meier analysis, log rank test, and Cox regression.

Results: The relapse rate was $30.42 \%$, mean and median of the time to relapse (survival time) were $27.40 \pm 1.63$ months (CI 95\%: 24.19-30.60) and $25 \pm 2.25$ months (CI 95\%: $22.5-27.5$ ), respectively. In the first six months, the cumulative survival rate was $83 \%$, while in the 24 th month it was $46 \%$ and the following time was consistent. Job status $(\mathrm{OR}=2.64)$, marital status $(\mathrm{OR}=1.55)$, family size $(\mathrm{OR}=1.20)$ and age $(\mathrm{OR}=0.23)$ were statistically significant in Cox regression model.

Conclusions: In the initial treatment, it seems necessary to supervise and monitor the treatment process through staff in addiction treatment centers together with the company of the addicts' families to reduce relapse rate.
\end{abstract}

Keywords: Drug Abuse; Behaviors; Addictive; Substance Abuse Treatment Centers

\section{Background}

Drug abuse is a lifestyle disease and a chronic and enduring phenomenon, which is among the important challenging and costly health problems, leading to physical, mental and psychiatric outcomes in persons, families and communities (1-4). In Iran, the drug abuse was reported as the third leading cause of disease burden for males in 2003 (5). According to the recent national survey of drug abuse, 1.2 million of addicts need treatment services in Iran (1). Opium and heroin were reported as the main drugs of abuse, respectively. However, in the recent years, drug abuse has accrued an important shift from opium use towards using heroin (1-6). The anti-narcotic laws have been approved to the extension of addiction treatment and reduction programs have been performed since 1997 by Iran. The most important program for reducing drug abuse was establishing methadone maintenance treatment (MMT) centers (7). Relapse following the beginning of drug abuse treatment is a common outcome (8). In addition, the treatment success rates of addicts in these centers were different. Previously, a survey showed a six-month retention rate of about $23 \%$ which often required overtime treatment $(9,10)$. In another study, Sadegiye indicated a relapse rate of about $80 \%$ at the first six-month treatment (11). Furthermore, researches in the last decade have revealed increase of drug usage in most countries $(12,13)$. It is believed that drug abuse is viewed as a chronic disorder; however, relapse is considered as the natural section of the recovery process, which is defined when subjects return to even a single usage of a drug, same as the condition prior to treatment (14). Some researches, related to methadone maintenance programs in treatment centers, showed that although treatment with methadone can be efficient for risk factors such as decreasing the crime-associated incidents, employment increase and the improvement of quality of life for addicts, many subjects continue drug abuse with concurrent use of methadone (12). Several factors are involved in the drug abuse relapse, which are determined by interaction of individual, environmental, and physiological factors (15). A period over $75 \%$ of all drug abuse relapses were found related to involve interpersonal struggle, lack of social and family support, socio-economic risk factors, negative psychological states, and some of demographic variables such as age and employment status (15-17). The spent time with others and unpleasant emotions were the most important causes of relapse in

Copyright (C) 2015, Zahedan University of Medical Sciences. This is an open-access article distributed under the terms of the Creative Commons Attribution-NonCommercial 4.0 International License (http://creativecommons.org/licenses/by-nc/4.0/) which permits copy and redistribute the material just in noncommercial usages, provided the original work is properly cited. 
the study conducted by Shafiei et al. in Iran (18). In addition, the accruing of relapse increases in persons with insufficient job skills who are exposed to high-risk situations (15). The relationship between psychiatric disorders and drug abuse relapse after treatment may be bi-directional, prior to relapse, coping with persistent psychiatric symptomatology, and specially increase in the intensity of symptomatology can affect the risk of drug abuse relapse. Additionally, the relapse risk of drug abuse may differ by the types of psychiatric symptoms experienced. The relapse after treatment can influence the psychiatric symptomatology. The side-effects of drugs used by patients can change particular psychiatric symptoms (cocaine intoxication can increase irritability). Drug abuse relapse may also lead to environmental stressors, such as struggle with family and criminal acts, which may accelerate psychiatric symptoms $(19,20)$.

\section{Objectives}

Interpretation of relapse situations needs a prerequisite for the identifying persons with high-risk situations. In addition, the efficient treatment of addiction requires treatment planning, adequate knowledge for policy-making, and determination of characteristics and background variables regarding drug use by addicts to reduce addiction relapse. A few surveys are available on addicts to seek addiction relapse in treatment centers in Iran. Few researches have specifically focused on drug abuse using survival analysis method. Therefore, the present study investigated the relapse rates and patterns of drug abuse relapse and their determinant in addicts of treatment centers in Ilam city, Iran, using the survival analysis method.

\section{Patients and Methods}

This survey was a retrospective cohort design conducted in four addiction treatment centers in Ilam, Iran, in 2012. The target population comprised all self-referred addicts who had been treated in those centers. Sample size was calculated by Equation 1:

$$
\frac{\left(\mathrm{Z}_{1-\frac{a}{2}}\right)^{2} \times \mathrm{P}(1-\mathrm{P})}{\mathrm{d}^{2}}=\frac{(1.96)^{2} \times 0.38(1-0.62)}{0.08^{2}}
$$

$\left(\mathrm{Z}_{1-\alpha \mid 2}\right.$ : level of significance 5\%, P: prevalence of relapse in a previous study (9), D: absolute precision). Cluster sampling method was used for selecting the centers because all the addiction treatment centers get the same fees from their subjects, and partly, all the centers were similar in different aspects. In terms of the subjects cost, variation between the centers is small. The centers provided the same services based on the reports of the ministry of health in Iran (1). Therefore, four addiction treatment centers were selected among eight centers randomly; thus, all the addicts' records in the four centers were considered from 2008 - 2012 and subjects with eligible crite- ria were entered to study. In total, 140 males were selected for this research. Relapse was defined as the subjects returned to even a single usage of a drug or more (14). The inclusion criteria were treatment with methadone for at least one month and accurate registration date of the treatment beginning. The data were collected by interview and referred to records with questions including demographic variables such as age, sex, marital status, job status and relevant information including addiction history in family, family size, drug abuse history, kind of drug, relapse status and time of treatment to relapse (per month). In addition, subjects were provided with a complete description of the study and written informed consents were obtained. This study was approved by the ethics committee of Ilam University of Medical Sciences. The gathered data from the subjects were analyzed using SPSS-21 software, through the life table, Kaplan-Meier analysis, log rank test, and Cox regression (conditional forward method), which are applicable statistics methods for analyzing studies conducted as follow-up time design. Moreover, we considered the base at the P value cut-off point of $0.25(20)$ in the univariate analysis (log rank test); the variables with P value $\leq 0.25$ were entered to multivariate analysis (Cox regression). The level of significance was considered 0.05 .

\section{Results}

The mean and the standard deviation (SD) of variables of age, family size, addiction history and time of follow-up were obtained as $31.03 \pm 7.68$ years, $5.01 \pm$ 2.16 individuals, $9.47 \pm 7.51$ years and $17.18 \pm 1.24$ months, respectively. In addition, the relapse rate was $30.42 \%$ based on the total time. The subjects with relapse constituted $43.6 \%$ ( 61 subjects) of the study, while subjects without relapse in the time lag of survey constituted only $56.4 \%$ (79 subjects). Other characterizations of the participants' survival times are shown in Table 1. According to Table 1, the log rank test analysis revealed that the time to relapse of the married subjects was more than the other groups. In addition, subjects who used opium had a higher time to relapse compared to subjects who used other types of drugs. Nevertheless, there was no significant difference in the time to relapse based on the variable of addiction in family. Other information are also shown in Table 1. Based on Table 2, the most relapses occurred within the first six months and it reduced in other intervals. In addition, cumulative survival index showed that in the first six months, about $83 \%$ of the subjects did not experience relapse to drug abuse, while this index was around $46 \%$ in the 24th month and was consistent in the next follow-up. The results of the Kaplan-Meier method showed that mean and SD of the time to relapse was $27.40 \pm 1.63$ months (CI 95\%: 24.19 - 30.60) and the median of time to relapse was obtained $25 \pm 2.25$ months (CI 95\%:22.5 27.5). The diagram of time to relapse (survival diagram) with the Kaplan-Meier method is shown in Figure 1. A 
Cox regressing model with conditional forward method was used to evaluate the association of all the significant variables with relapse to drug abuse. The final model is indicated in Table 3. The results of this analysis indicated that after adjusting the other factors, job sta- tus had the most association with relapse to drug abuse $(\mathrm{OR}=2.46$; $\mathrm{CI} 95 \%$ : 1.35 - 5.19). In addition, the variables including the education status $(\mathrm{P}=0.10)$, addiction in family $(P=0.30)$ and addiction history $(P=0.15)$ were removed from the cox regression model.

Table 1. Characterization of Participations and Their Survival Times

\begin{tabular}{|c|c|c|c|c|}
\hline Categorization & Values $^{\mathrm{a}}$ & Survival Time Mean, mo & CI 95\% & P Value $^{\mathrm{b}}$ \\
\hline Marital Status & & & & 0.03 \\
\hline Single & $65(46.4)$ & 22.94 & $18.70-27.17$ & \\
\hline Married & $66(47.1)$ & 31.23 & $26.81-35.65$ & \\
\hline Widow and divorced & $9(6.4)$ & 15.11 & $9.27-20.94$ & \\
\hline Job Status & & & & 0.01 \\
\hline Employed & $67(47.9)$ & 32.14 & $28.28-36.54$ & \\
\hline Unemployed & $70(50)$ & 19.89 & $15.90-23.89$ & \\
\hline Retired & $3(2.1)$ & 24 & $24-24$ & \\
\hline Education & & & & 0.02 \\
\hline Illiterate & $13(9.3)$ & 27.41 & $20.42-34.40$ & \\
\hline Primary and middle school & $49(35)$ & 19.13 & $14.52-23.75$ & \\
\hline High-school diploma & $61(43.6)$ & 31.57 & $26.90-36.24$ & \\
\hline Academic education & $17(12.1)$ & 30.49 & $21.17-39-80$ & \\
\hline Addiction history in family & & & & 0.95 \\
\hline Yes & $45(32.1)$ & 27.37 & $22.18-32.56$ & \\
\hline No & $95(67.9)$ & 27.65 & $23.61-31.69$ & \\
\hline Drug & & & & 0.03 \\
\hline Opium & $67(47.9)$ & 31.05 & $26.57-35-54$ & \\
\hline Other & $73(52.1)$ & 24.11 & $19.68-28-55$ & \\
\hline
\end{tabular}

a Data are presented as No.(\%).

$\mathrm{b}$ Used from the log rank test.

\begin{tabular}{|c|c|c|c|c|c|c|}
\hline $\begin{array}{l}\text { Follow-up Intervals, } \\
\text { month }\end{array}$ & With Drawl, No. & $\begin{array}{c}\text { Exposed to Risk, } \\
\text { No. }\end{array}$ & Relapse, No. & $\begin{array}{c}\text { Survival } \\
\text { Rate }\end{array}$ & $\begin{array}{l}\text { Cumulative } \\
\text { Survival }\end{array}$ & Hazard Rate \\
\hline 1 - 6 & 12 & 134 & 23 & 0.83 & 0.83 & 0.03 \\
\hline $6-12$ & 7 & 101 & 13 & 0.87 & 0.72 & 0.02 \\
\hline $12-18$ & 8 & 81 & 11 & 0.86 & 0.62 & 0.02 \\
\hline $18-24$ & 14 & 59 & 9 & 0.85 & 0.53 & 0.03 \\
\hline $24-30$ & 7 & 39 & 5 & 0.87 & 0.46 & 0.02 \\
\hline $30-36$ & 18 & 55 & 0 & 1 & 0.46 & 0 \\
\hline $36-42$ & 10 & 8 & 0 & 1 & 0.46 & 0 \\
\hline $42-48$ & 3 & 1 & 0 & 1 & 0.46 & 0 \\
\hline
\end{tabular}


Kassani A et al.

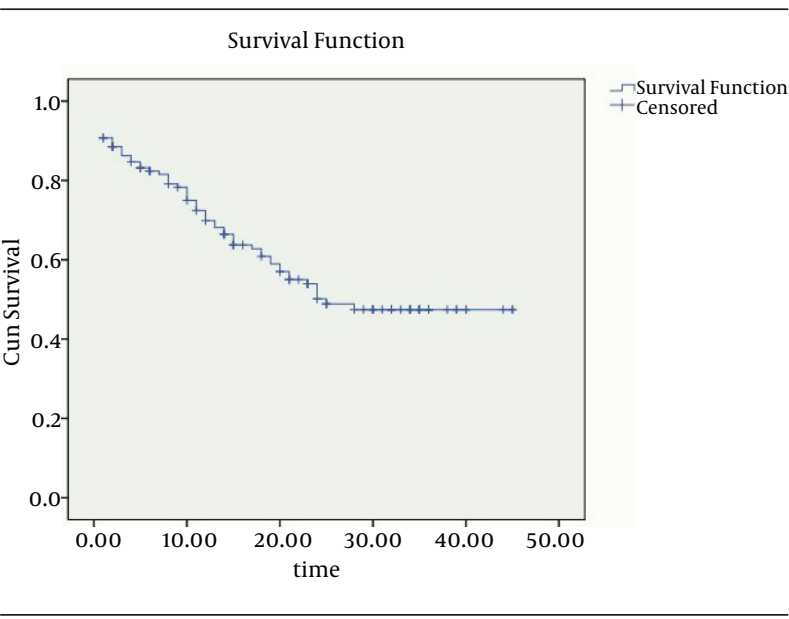

Figure 1. Survival Diagram Using the Kaplan-Meier Method

Table 3. Associated Variables With Relapse to Drug Abuse in Cox Regressing Model $^{\mathrm{a}}$

\begin{tabular}{lccccc}
\hline Variables & B & SE & Wald & $\begin{array}{c}\text { OR Ad- } \\
\text { justed }\end{array}$ & CI 95\% \\
\hline Age & -0.07 & 0.02 & 11.46 & 0.93 & $\begin{array}{c}0.89- \\
0.97\end{array}$ \\
\hline Family size & 0.18 & 0.07 & 6.16 & 1.20 & $1.02-$ \\
& & & & & 4.94 \\
\hline $\begin{array}{l}\text { Marital status } \\
\text { (married/single) }\end{array}$ & 0.44 & 0.35 & 0.48 & 1.55 & $\begin{array}{c}1.21- \\
\text { Job status }\end{array}$ \\
\hline
\end{tabular}

a Abbreviations: B, Unstandardized (B) coefficien; C, confidence interval; OR, Odds Ratio; SE, Standard Error.

\section{Discussion}

In the present survey, the rate and time to relapse episode (survival time) and their determinants following the treatment for drug abuse were described. In brief, the relapse rate of $30.4 \%$ in this study was similar to the relapse rates summarized by Greenwood et al. and Ramo and Brown, and Brown et al. $(8,10,15)$. However, in a study by Shafiei, the relapse prevalence was around 70\% during 12 months (18). Therefore, it is necessary to monitor and supervise the addicts treatment to reduce the relapse rate, which should be implemented more effectively and accompanied with the contribution of addicts' families (21). Based on the life table model, most of the relapses of drug abuse accrued in the first six months of the treatment (23 of 61 evens), which was approximately consistent with previous studies $(10,22)$. These differences can be due to erratic and cyclic periods of relapse and abstinence in addicts (15). The survival accumulations at the end of $6,12,18$, 24 and 30 months in the subjects were $83 \%, 72 \%, 62 \%, 53 \%$, and $43 \%$, respectively. In the first six months, $83 \%$ of the under treatment addicts did not return to drug abuse. There was no relapse to drug abuse (survival rate $=100 \%$ ) after the 30th month of the treatment. However, accumulative survival that reveals the possibility of return to drug abuse in the previous intervals was around $46 \%$ in the 30th month and consistent after the 30th month of the treatment. In other words, the most possible time of drug abuse relapse was during one to six months following the beginning of treatment and the lowest risk to relapse was after the 30th month. Further, when we look deeply at the Kaplan-Meier diagram in Figure 1, we can have a better understanding of this finding. There were noteworthy differences in the survival time between the married, single and widowed or divorced subjects, which were 31.23 (CI 95\%: 18.70 - 27.17), 22.94 (CI 95\%: 18.70 - 27.17) and 15.11 (9.27 - 20.94) months, respectively. Sau and Mukherjee argued that lower relapse rate in married people rather than singles and divorced or separated persons can be due to family support and financial security, which are critical for recovery and social rehabilitation (14). In addition, in the study of Hosseini, marital duration played a significant role in relapse time (16). The association between the survival time and job status was statistically significant $(\mathrm{P}=$ 0.01). The mean of survival time was 32.14 months (CI 95\%: 28.28 - 36.54) in the employed subjects, 19.89 (CI 95\%:15.90 -23.89) in unemployed, and 24 months in the retired subjects. Several studies have documented the association between addiction treatment relapse and employment status $(16,22,23)$; for instance, there is a report of association between employment and addiction relapse reduction (23), a positive correlation between employment and lower rates of drug abuse relapse as well as longer term heroin abstinence (24). Richardson believed that employment is usually upheld as a main consequence, indicator of the context of drug abuse treatment and recovery (17). In fact, any reduction in subjects' income due to economic adversity as unemployment can efficiently worsen the access to drug abuse treatment services $(7,25)$. In contrast, a few studies have indicated that employment is a risk factor for drug abuse treatment outcome, which supports the assumption that employment with providing an income source and reinforcement of the lives of addicts can encourage them to continue the drug abuse $(17,26)$. In adolescents, the drug use patterns and circumstances are different from adults. In the situations that a group of under-treatment friends use drugs, the probability of return to drug is higher in teenagers than in adults. Consequently, the characteristics of adolescent relapse may also vary $(17,27)$, which was similar to the findings of the present study (OR=0.93 CI 95\%: 0.89-0.97). The treatment outcome of relapse is dependent on social and economic status in each country, based on the Universal Declaration of Human Rights which states that "everybody has the right to a standard living for the well-being and health of him/herself and of his/her family, such as food, clothing, housing and medical care and necessary social services"; thus, access to suitable healthcare is a right. Certainly, addiction and its associated consequences such as relapse are not restricted to people in a certain country $(28,29)$. 
Kassani A et al.

Ultimately, the prevention of return to drug abuse is a multifactorial approach which necessitates expertise and specific skills. Recognizing the rate, patterns and processes of relapse risk factors is a main strategy which can be achieved with effort, providing the unset of addicts' treatment. In this method, addiction treatment centers with supports of addicts families can distinguish situations related with a higher risk to reducing the rate of drug abuse relapse. Furthermore, suitable medical and psychological interventions can be efficient to reduce relapse simultaneously $(18,30)$.

As limitations of our study may be the recall and misclassification biases, which could not be totally excluded because some information were not registered in the subjects' records and were collected through interview. A few researches have specifically focused on the drug abuse relapse using survival analysis, which can be considered as one the advantages of the present study. In the initial treatment, it seems necessary to supervise and monitor the treatment process through staff in addiction treatment centers with the company of addicts' families to reduce the relapse rate. In addition, the treatment is a complex process, dependent on demographical, environmental, psychological and therapeutic factors. The determinants of drug abuse relapse in the present study were age, marital status, family size and job status of subjects, regarded in programs of addiction treatment. Perhaps, the most important finding from the survival analysis of addiction relapse was the association of employment and relapse; thus, it is necessary to be carefully taken into account by policy makers and authorities in the field of addiction and conduct more detailed studies in specific job groups of addicts under treatment.

\section{Acknowledgements}

This study was supported by the research center for prevention of socio-psychological injuries in Ilam university of medical sciences with the grant number $13 / 7 / 852$. We are also grateful to all the staff and managers of addiction treatment centers in Ilam city who helped us to conduct this research.

\section{Authors' Contributions}

Aziz Kassani, Jafar Hassanzadeh, Mohsen Niazi and Rostam Menati contributed to conceiving and designing of the study. The data was collected by Aziz Kassani and Rostam Menati. The gathered data were analyzed and interpreted jointly by Aziz Kassani and Jafar Hassanzadeh, Mohsen Niazi and Rostam Menati. Aziz Kassani and Jafar Hassanzadeh contributed equally in writing the manuscript. All the authors had equal shares in revising and approving the manuscript.

\section{References}

1. Shekarchizadeh H, Ekhtiari H, Khami MR, Virtanen JI. Patterns of pre-treatment drug abuse, drug treatment history and characteristics of addicts in methadone maintenance treatment in Iran. Harm Reduct J. 2012;9:18.
2. Steketee JD, Kalivas PW. Drug wanting: behavioral sensitization and relapse to drug-seeking behavior. Pharmacol Rev. 2011;63(2):348-65.

3. World Health Organization DOMHASA. Guidelines for the psychosocially assisted pharmacological treatment of opioid dependence. Geneva: WHO; 2009. Available from: http://www.who.int/substance_abuse/publications/9789241547543/en/.

4. karajibani M, Montazerifar F, Shakiba M. Evaluation of Nutritional Status in Drug Users Referred to the Center of Drug Dependency Treatment in Zahedan. Int J High Risk Behav Addict. 2012;1(1):16-9.

5. Naserbakht M, Djalalinia S, Tayefi B, Gholami M, Eftekhar Ardabil $M$, Shariat SV, et al. National and sub-national prevalence, trend, and burden of mental disorders and substance abuse in Iran: 1990 - 2013, study protocol. Arch Iran Med. 2014;17(3):182-8.

6. Zerell U, Ahrens B, Gerz P. Documentation of a heroin manufacturing process in Afghanistan. Bulletin on Narcotics;2007. p. 11.

7. Shariatirad S, Maarefvand M. Sanctions against Iran and the impact on drug use and addiction treatment. Int J Drug Policy. 2013;24(6):636-7.

8. Greenwood GL, Woods WJ, Guydish J, Bein E. Relapse outcomes in a randomized trial of residential and day drug abuse treatment. J Subst Abuse Treat. 2001;20(1):15-23.

9. Shirinbayan P, Rafiey H, Vejdani Roshan A, Narenjiha H, Farhoudian A. Predictors of retention in methadone maintenance therapy: a prospective multi-center study. Sci Res Essay. 2010;5(21):3231-6.

10. Ramo DE, Brown SA. Classes of substance abuse relapse situations: a comparison of adolescents and adults. Psychol Addict Behav. 2008;22(3):372-9.

11. Sadegiye Ahari S, Azami A, Barak M, Amani F, Firuz S. Reviewing the causes of recurred addiction in patients who referred to centers introduced of Tehran welfare. Ardabil Med Univ J. 2004;3(4):36-40.

12. Chaney EF, Roszell DK, Cummings C. Relapse in opiate addicts: a behavioral analysis. Addict Behav. 1982;7(3):291-7.

13. Gerwe CF. Chronic addiction relapse treatment: a study of the effectiveness of the high-risk identification and prediction treatment model. Part III. Conclusion and future implications of HRIPTM research.J Subst Abuse Treat. 2000;19(4):439-44.

14. Sau M, Mukherjee A, Manna N, Sanyal S. Sociodemographic and substance use correlates of repeated relapse among patients presenting for relapse treatment at an addiction treatment center in Kolkata, India. Afr Health Sci. 2013;13(3):791-9.

15. Brown SA, Vik PW, Creamer VA. Characteristics of relapse following adolescent substance abuse treatment. Addict Behav. 1989;14(3):291-300.

16. Hosseini S, Moghimbeigi A, Roshanaei G, Momeniarbat F. Evaluation of drug abuse relapse event rate over time in frailty model. Osong Public Health Res Perspect. 2014;5(2):92-5.

17. Richardson L, Wood E, Montaner J, Kerr T. Addiction treatmentrelated employment barriers: the impact of methadone maintenance. J Subst Abuse Treat. 2012;43(3):276-84.

18. Shafiei E, Hoseini AF, Bibak A, Azmal M. High risk situations predicting relapse in self-referred addicts to bushehr province substance abuse treatment centers. Int J High Risk Behav Addict. 2014;3(2):e16381.

19. Tomlinson KL, Tate SR, Anderson KG, McCarthy DM, Brown SA. An examination of self-medication and rebound effects: Psychiatric symptomatology before and after alcohol or drug relapse. Addict Behav. 2006;31(3):461-74.

20. Khantzian EJ. The self-medication hypothesis of addictive disorders: focus on heroin and cocaine dependence. Am J Psychiatry. 1985;142(11):1259-64.

21. Leukefeld CG, Tims FM. Relapse and recovery: some directions for research and practice. NIDA Res Monogr. 1986;72:185-90.

22. Cornelius JR, Maisto SA, Pollock NK, Martin CS, Salloum IM, Lynch $\mathrm{KG}$, et al. Rapid relapse generally follows treatment for substance use disorders among adolescents. Addict Behav. 2003;28(2):381-6.

23. Hser YI. Predicting long-term stable recovery from heroin addiction: findings from a 33-year follow-up study. J Addict Dis. 2007;26(1):51-60.

24. Hser YI, Hoffman V, Grella CE, Anglin MD. A 33-year follow-up of narcotics addicts. Arch Gen Psychiatry. 2001;58(5):503-8. 


\section{Kassani A et al.}

25. Compton WM, Thomas YF, Stinson FS, Grant BF. Prevalence, correlates, disability, and comorbidity of DSM-IV drug abuse and dependence in the United States: results from the national epidemiologic survey on alcohol and related conditions. Arch Gen Psychiatry. 2007;64(5):566-76.

26. Magura S, Staines GL, Blankertz L, Madison EM. The effectiveness of vocational services for substance users in treatment. Subst Use Misuse. 2004;39(13-14):2165-213.

27. Liddle HA. Treating adolescent substance abuse using multidimen- sional family therapy. American Psychological Association; 2010 Available from: http://psycnet.apa.org/psycinfo/2010-09488-027.

28. Freeman M. Human rights: an interdisciplinary approach. Polity; 2011. pp. 176-211.

29. Marlatt GA, Donovan DM. Relapse prevention: Maintenance strategies in the treatment of addictive behaviors. Guilford Press; 2005.

30. Bowen S, Chawla N, Collins SE, Witkiewitz K, Hsu S, Grow J, et al. Mindfulness-based relapse prevention for substance use disorders: a pilot efficacy trial. Subst Abus. 2009;30(4):295-305. 